\title{
Topical application of sphingosine 1-phosphate receptor 1 prolongs corneal graft survival in mice
}

\author{
JING ZHU ${ }^{1}$, YONG LIU ${ }^{2}$ and YIFEI HUANG ${ }^{3}$ \\ ${ }^{1}$ Department of Ophthalmology, The First Affiliated Hospital of the Chinese PLA General Hospital, Beijing 100038; \\ ${ }^{2}$ Department of Ophthalmology, Chinese PLA Air Force General Hospital, Beijing 100038; \\ ${ }^{3}$ Department of Ophthalmology, Chinese PLA General Hospital, Beijing 100853, P.R. China
}

Received November 26, 2013; Accepted July 21, 2014

DOI: $10.3892 / \mathrm{mmr} .2015 .3230$

\begin{abstract}
The present study aimed to investigate the effects of topical application of sphingosine 1-phosphate receptor 1 (S1P1) on allogeneic corneal transplantation in mice. A total of $45 \mathrm{BALB} / \mathrm{c}$ mice received corneal grafts from $\mathrm{C} 57 \mathrm{BL} / 6$ donors. The recipients were randomly divided into three groups and treated with eye drops containing $0.5 \%$ S1P1, $1 \%$ cyclosporine A or saline as a negative control. The serum levels of interleukin (IL)-2, IL-10, tumor growth factor (TGF)- $\beta 1$ and interferon (IFN)- $\gamma$ were measured by ELISA. The numbers of CD4+ T cell and T-regulatory (Treg) cell phenotypes were measured by flow cytometry. The cytokine mRNA expression was analyzed by quantitative polymerase chain reaction. The results demonstrated that corneal graft survival was prolonged in the S1P1 group [mean survival time (MST), 24.11 \pm 1.58 days], and $1 \%$ cyclosporine A (MST, $25.0 \pm 1.91$ days) compared with the controls (MST, 13.44 \pm 0.48 days; $\mathrm{P}<0.01)$. S1P1 and cyclosporine A decreased CD4+ T-cell levels $(\mathrm{P}<0.05)$ in the peripheral blood compared with those of the controls. However, an increase of CD4+ T cells in the spleen was noted in the S1P1 group $(\mathrm{P}<0.05)$ and Treg cells were also increased in the cervical lymph nodes in the S1P1 group $(\mathrm{P}<0.01)$. TGF- $\beta 1 \mathrm{mRNA}$ transcription in the corneal grafts increased following treatment with $\mathrm{S} 1 \mathrm{P} 1(\mathrm{P}<0.05)$ and TGF- $\beta 1$ in the serum following treatment with S1P1 also increased $(\mathrm{P}<0.01)$. In conclusion, $\mathrm{S} 1 \mathrm{P} 1 \mathrm{had}$ a significant effect in corneal allograft rejection inhibition.
\end{abstract}

\section{Introduction}

Corneal disease is the second most frequent cause of blindness amongst ocular diseases (1). A number of these cornea

Correspondence to: Professor Jing Zhu, Department of Ophthalmology, The First Affiliated Hospital of the Chinese PLA General Hospital, 51 Fucheng Road, Haidian, Beijing 100038, P.R. China E-mail: cnzjdoc@163.com

Key words: sphingosine 1-phosphate receptor 1, allogeneic corneal, transplantation, corneal disease conditions, including inflammation or infection, are treated with medication. For more severe cases which are not treatable with these strategies, or in cases where there is scarring or cloudiness of the cornea resulting in visual loss, corneal transplantation may be required to improve vision. Corneal transplantation, which is also known as penetrating keratoplasty, is one of the most common and successful types of solid organ transplantation in humans (2). However, Williams et al (3) reported that the probability of survival of patients following penetrating corneal graft survival in an Australian cohort was 87, 73,60 and 46\% at 1, 5, 10 and 15 years. In addition, in high-risk grafts which have either received a previous corneal transplant or which have prevascularized graft beds, the success rate is markedly reduced, often as low as $20-40 \%$ (4). Irreversible immune rejection of the transplanted cornea is the major cause of human allograft failure in the intermediate and late postoperative period (5). The corneal graft rejection is a complex immune process consisting of a sequence of events. Corneal allograft rejection requires $\mathrm{T}$ cells, amongst which $\mathrm{CD} 4+\mathrm{T}$ cells are the most important T-cell population, and two ocular antigen-presenting cell populations - corneal Langerhans cells and conjunctival macrophages - are required (6). Previously, a number of studies have identified that corneal allograft survival is associated with the CD4+CD25+Foxp3+ T-regulatory cells (Treg cells) $(7,8)$.

Currently available immunosuppressive drugs, including corticosteroids and cyclosporin A (CsA), are used to prevent or treat corneal graft rejection in humans. However, the long-term survival of corneal grafts, particularly in high-risk recipients, was not achieved with satisfaction $(9,10)$. Therefore, novel strategies to achieve long-term survival of corneal grafts, particularly in high-risk recipients, are required. As a synthetic structural analog of myriocin, sphingosine-1-phosphate (S1P)1 is a potent immunosuppressant which prolongs allograft survival (11). Once it is phosphorylated in vivo by sphingosine kinase 2 (SphK2), FTY720-P acts as an agonist on four of the five known S1P receptors (S1P1, S1P3, S1P4, and S1P5) (12). By contrast to classical immunosuppressants, it has been proved that S1P1 does not interfere with T-cell proliferation, but induces a severe deprivation in lymphocytes in the blood due to modification of S1P signaling (13). Oral administration of a selective agonist of the S1P receptor type 1 (S1P1) induced 
a profound and reversible reduction in circulating lymphocytes and prolonged the survival of cardiac allografts in stringent rat transplantation (14). Sedláková et al (15) found that intraperitoneal injections of FTY720 prolonged the graft survival in rat-to-mouse corneal xenografts. Another two studies also found that oral immunosuppression with FTY720 significantly prolonged the survival of corneal allografts $(16,17)$. However, systemic FTY720 treatment was reported to cause non-fatal herpesvirus infections, bradycardia and atrioventricular block, hypertension, macular edema, skin cancer and elevated liver-enzyme levels (18). Therefore, in order to avoid the side effects of systemically administered immunosuppressants, the present study topically administered S1P1 to mice following allogeneic corneal transplantation.

\section{Materials and methods}

Animals. Orthotopic corneal transplantation was performed using inbred BALB/c and C57BL/6 male six- to eight-week-old mice. The mice used in grafting experiments weighed $18-22 \mathrm{~g}$. C57BL/6 mice served as donors and BALB/c mice were recipients of the corneal allografts. These were fully mismatched for major histocompatibility complex (MHC) and multiple minor histocompatibility antigens between the two inbred mouse strains. The mice were obtained from Beijing HFK Bio-Technology Co., Ltd. (Beijing, China). The present study was conducted in strict accordance with the recommendations in the Guide for the Care and Use of Laboratory Animals of the National Institutes of Health. The animal use procedure was reviewed and approved by the Institutional Animal Care and Use Committee of the PLA General Hospital (Beijing, China).

Orthotopic allogeneic corneal transplantation. A total of $45 \mathrm{BALB} / \mathrm{c}$ mice received corneal grafts from C57BL/6 donors. Prior to all surgical procedures, the mice were deeply anesthetized by intraperitoneal injection of $3 \%$ pentobarbital sodium (50 mg/kg, Nembutal; Beijing Chemical Co., Beijing, China). Tropicamide-phenylephrine ophthalmic solution (Santen Pharmaceutical Co., Ltd., Osaka, Japan) was topically applied to dilate the pupils of both the donors (C57BL/6) and the recipients $(\mathrm{BALB} / \mathrm{c})$. The donors' cornea was prepared according to the 'underwater technique' originally described by Zhang et al (19). The central $2.0 \mathrm{~mm}$ of a C57BL/6 cornea were marked with a $2.0-\mathrm{mm}$ trephine, excised with Vannas scissors and placed into balanced salt solution $\left(\mathrm{BSS}^{\mathrm{TM}}\right.$, Alcon Co., USA), prior to grafting. The donor cornea graft was sutured into a $1.5-\mathrm{mm} \mathrm{BALB} / \mathrm{c}$ recipient corneal bed with 8-10 interrupted 11-0 nylon sutures (Sharpoint ${ }^{\mathrm{TM}}$, Reading, PA, USA). The anterior eye chamber was restored at the end of surgery by injecting air. Corneal sutures were removed on day 10 following transplantation. The recipient mice were treated in situ with ophthalmic gel containing S1P1 (provided by the Department of Molecular Drug Design, Institute of Pharmacology and Toxicology Sciences, Beijing, China) at a concentration of $5 \mathrm{mg} / \mathrm{ml}(0.5 \%)$ following transplantation, which was performed successively from days 0-30. The recipient mice which received CsA eye drops $(10 \mathrm{mg} / \mathrm{ml}, 1 \%$, North China Pharmaceutical Group Co., Ltd., Hebei, China) served as positive controls. The recipient mice which received in situ ophthalmic gels without any drugs served as negative controls.

Clinical evaluation of grafted corneas. The degree of opacity as well as the degree of neovascularization was evaluated daily within the first postoperative two weeks and then three times weekly for up to 30 days. Briefly, donor corneal opacity score (0-4), edema score (0-2) and neovascularization score (0-4) were graded according to criteria previously described (20). Rejection was defined as the day on which indices of opacity, edema and neovascularization reached moderate or severe levels, with an opacity score $\geq 3$ and a total $\geq 5$, in grafts which had been transparent following operation (21). The grafts with technical difficulties, including intraocular hemorrhage, cataract or infection, were excluded.

ELISA. Standard ELISA assays were used to measure the serum autoantibody production on day 30 following transplantation. To prepare the serum samples, peripheral blood (PBL) samples from the mice were maintained on ice for $2 \mathrm{~h}$, centrifuged at $1,000 \mathrm{x} \mathrm{g}$ for $20 \mathrm{~min}$ at $4^{\circ} \mathrm{C}$, and its supernatant was immediately separated from the pellet. The serum levels of IL-2, IL-10, TGF- $\beta 1$ and IFN- $\gamma$ were measured using a corresponding ELISA kit (Dakewe Biotech Co., Ltd., Shenzhen China). The plates were read using an ELISA microplate reader (DNM-9606; Nanjing Huadong Electronics Group Medical Equipment Co., Ltd., Nanjing, China) at an optical density (OD) of $450 \mathrm{~nm}$.

Flow cytometric analysis. The T-cell phenotype in the right cervical lymph node, the blood and the spleen from the experimental mice was analyzed by flow cytometry on day 30 following transplantation. The Treg cells were detected by a Mouse Regulatory T-cell Staining kit (phycoerythrin Foxp3 FJK-16s, fluorescein isothiocyanate CD4 and allophycocyanine CD25) from eBioscience (San Diego, CA, USA), according to the manufacturer's instructions (eBioscience). The data were acquired using a FACSCalibur flow cytometer (BD Biosciences, San Jose, CA, USA) and analyzed by using Winmid 2.9 software (http://scripps.edu/software.html; Scripps Institute, La Jolla, CA, USA). The cells were gated for $\mathrm{CD} 4+$ and the percentage of CD4+CD25+FoxP3+ cells was calculated.

Quantitative polymerase chain reaction ( $q P C R)$. Corneas were excised ( $2.5 \mathrm{~mm}$ in diameter), frozen in liquid nitrogen and stored at $-80^{\circ} \mathrm{C}$ on day 30 following transplantation. For intragraft gene expression analysis, the total cellular RNA was isolated using the TRIzol ${ }^{\circledR}$ (Invitrogen Life Technologies, Carlsbad, CA, USA) and liquid nitrogen. The reverse transcription of mRNA to cDNA was performed in $20 \mu \mathrm{l}$ reaction volumes with random priming and EasyScript RT using an Easy RT-PCR kit (Beijing TransGen Biotech Co., Ltd., Beijing, China). Gene expression was examined using an iCycler IQ Real-time PCR Detection System (Bio-Rad, Hercules, CA, USA) using the SYBR Green Realtime PCR Master Mix (Toyobo Co., Ltd., Osaka, Japan) with the respective qPCR primers for IL-2, IL-10, TGF- $\beta 1$, IFN- $\gamma$, Foxp 3 and GAPDH $(22,23)$. The primer sequences are used are provided in Table I. The cycle number at which the reporter fluorescence reached the threshold (CT value) was used for quantitative measurement. The relative expression data was determined by normalizing to GAPDH expression measured 
Table I. Primer sequences used for quantitative polymerase chain reaction.

\begin{tabular}{lll}
\hline Genes & \multicolumn{1}{c}{ Primer 1 (forward, $5^{\prime} \rightarrow 3^{\prime}$ ) } & \multicolumn{1}{c}{ Primer 2 (reverse, $\left.5^{\prime} \rightarrow 3^{\prime}\right)$} \\
\hline GAPDH & TGAAGGTCGGTGTGAACGGATTTG & GTTGAATTTGCCGTGAGTGGAGTC \\
IL-2 & GCACCCACTTCAAGCTCCA & AAATTTGAAGGTGAGCATCCTG \\
IL-10 & TGCCTTCAGCCAGGTGAAGACTTTC & CTTGATTTCTGGGCCATGCTTCTCTG \\
TGF- $\beta 1$ & ATACCAACTATTGCTTCAGCTCCACAG & GTACTGTGTGTCCAGGCTCCAAATAT \\
IFN- $\gamma$ & GCACAGTCATTGAAAGCCTAGAAAGTC & GGTAGAAAGAGATAATCTGGCTCTG \\
Foxp3 & ATGCCCAACCCTAGGCCAGCCAAG & TGGGCCCCACTTCGCAGGTCCCGAC \\
\hline
\end{tabular}
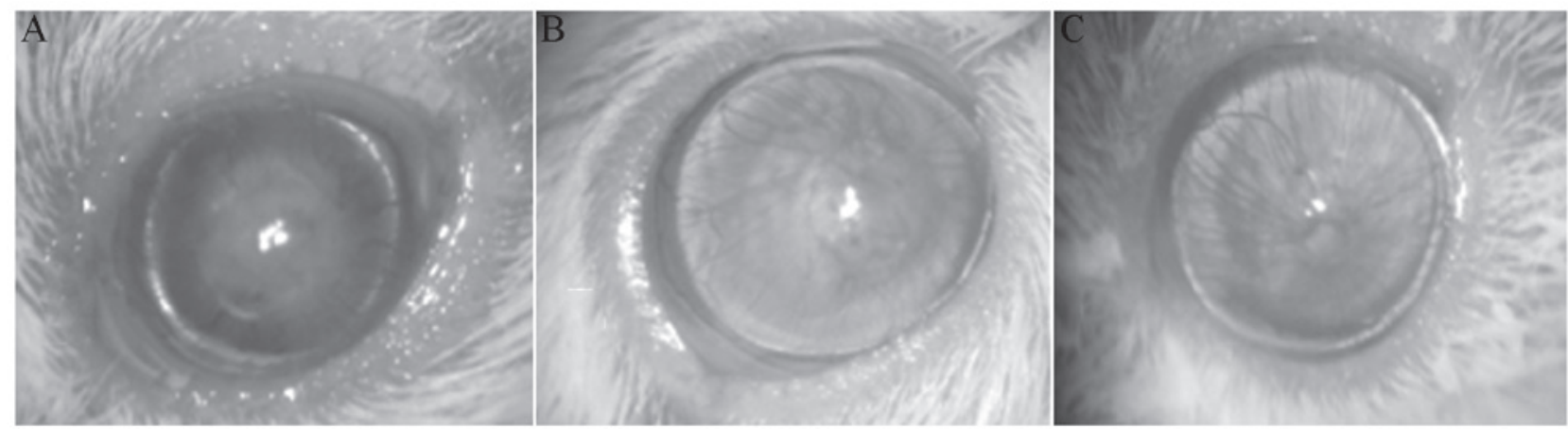

Figure 1. Opacity, edema and neovascularization of corneal grafts was observed at postoperative day 30. (A) Control group; (B) topical $0.5 \%$ sphingosine 1-phosphate receptor 1 group; (C) topical 1\% cyclosporin A group.

contemporaneously from the same sample to calculate a fold-change in value using the $2^{-\Delta \Delta \mathrm{CT}}$ method.

Statistical analysis. Actuarial graft survival was analyzed using the Kaplan-Meier survival method, and the log-rank test was used to examine for statistical differences among the groups. One-way analysis of variance followed by multiple comparisons with the Bonferroni test was used in all other cases. Statistical analyses were performed using SPSS 13.0 (SPSS, Inc., Chicago, IL, USA) In each case, $\mathrm{P}<0.05$ was considered to indicate a statistically significant difference and only significant probabilities are shown.

\section{Results}

Orthotopic allogeneic corneal transplantation. Transplantation of $\mathrm{C} 57 \mathrm{BL} / 6$ corneal grafts to $\mathrm{BALB} / \mathrm{c}$ recipients resulted in a rejection rate of $100 \%$ in the control group [mean survival time (MST), 13.44 \pm 0.48 days]. Compared with the control group, there were statistical differences both in the $0.5 \% \mathrm{~S} 1 \mathrm{P} 1$ ophthalmic gel group (MST, 24.11 \pm 1.58 days) and in the $1 \%$ CsA eye drop group (MST, 25.00 \pm 1.91 days) (both $\mathrm{P}<0.001$ ). The corneal allografts that were being rejected exhibited pronounced opacity, edema and neovascularization at postoperative day 30 (Fig. 1A). As demonstrated in Fig. 1B and C, the corneal allografts in the $0.5 \% \mathrm{~S} 1 \mathrm{P} 1$ and $1 \%$ CsA groups were clear.

ELISA. The serum levels of IL-2, IL-10, TGF- $\beta 1$ and IFN- $\gamma$ in the different groups are demonstrated in Fig. 2. Although the levels of IL-2 in the $1 \% \mathrm{CsA}$ eye-drop group were lower than those in the other groups, there were no statistically significant differences among these three groups $(\mathrm{P}>0.05$; Fig. 2A). The levels of IL-10 in the $1 \%$ CsA group and the $0.5 \%$ S1P1 group appeared higher than those in the control group (Fig. 2B). Compared with the control group, a strong secretion of TGF- $\beta 1$ in the $0.5 \%$ S1P1 group was observed $(\mathrm{P}<0.001$; Fig. 2C). Although the levels of IFN- $\gamma$ in the $1 \%$ CsA group and the $0.5 \%$ S1P1 group were lower than those in the control group, there was no statistically significant difference between the groups ( $\mathrm{P}>0.05$, Fig. 2D).

Flow cytometric analysis. Fig. 3 is an illustrative example of how the determination was performed by flow cytometry. A decrease in the mean percentage of CD4+ T cells in peripheral blood lymphocytes (PBLs) in the $1 \%$ CsA eye drop group and in $0.5 \% \mathrm{~S} 1 \mathrm{P} 1$ ophthalmic gel group were observed, compared with that in the control group $(\mathrm{P}=0.022$ and $\mathrm{P}=0.046$; Fig. 4A). There were no significant differences in the mean percentage of CD4+ T cells in the cervical lymph nodes among the three groups ( $\mathrm{P}>0.05$; Fig. 4B). Compared with the percentage of CD4+ T cells in the control group, an increase in the mean percentage of CD4+ T cells in the spleen in the $0.5 \%$ S1P1 ophthalmic gel group was observed $(\mathrm{P}=0.041$; Fig. 4C). With regard to the mean percentage of CD4+CD25+Foxp3+T cells in CD4+ T cells in PBLs, there was no statistically significant difference among the three groups ( $\mathrm{P}>0.05$; Fig. 5A). However, there was a significantly higher percentage of CD4+CD25+ Foxp3+T cells in CD4+ $\mathrm{T}$ cells in cervical lymph nodes in the $0.5 \% \mathrm{~S} 1 \mathrm{P} 1$ ophthalmic gel group when compared with that in the control group $(\mathrm{P}<0.001$; Fig. 5B). Consistent with the cervical lymph 
A

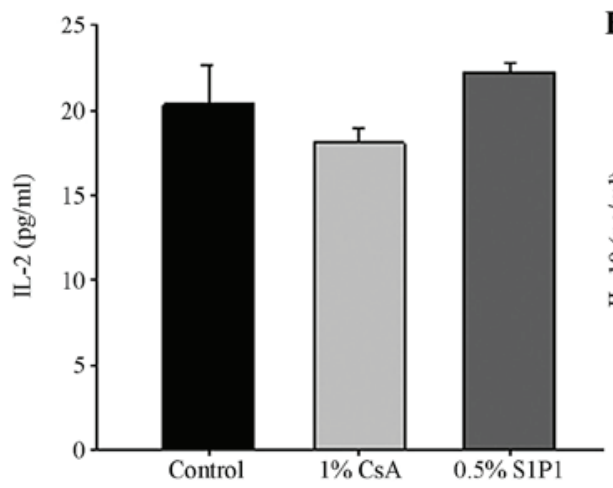

C

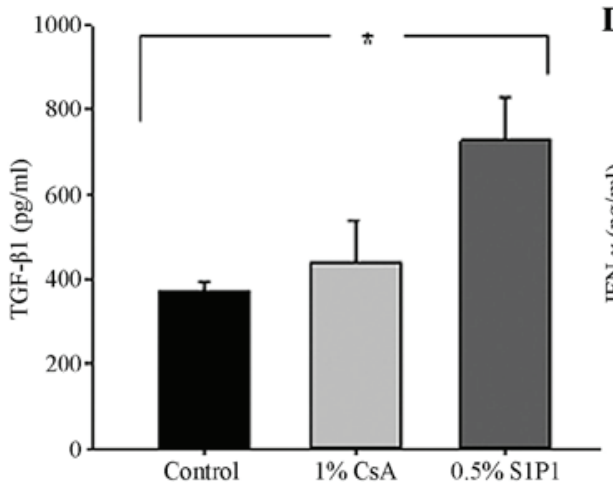

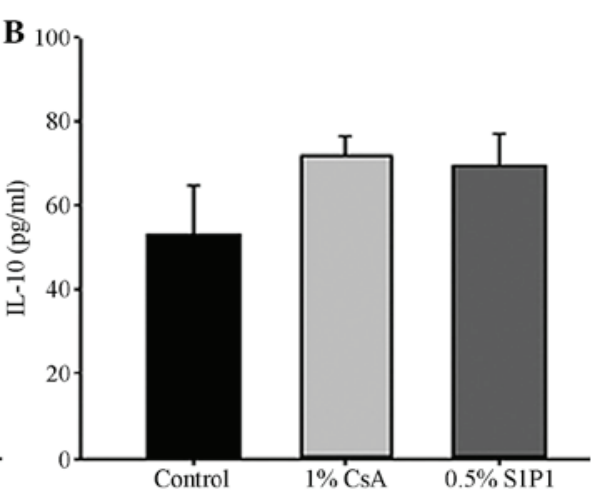

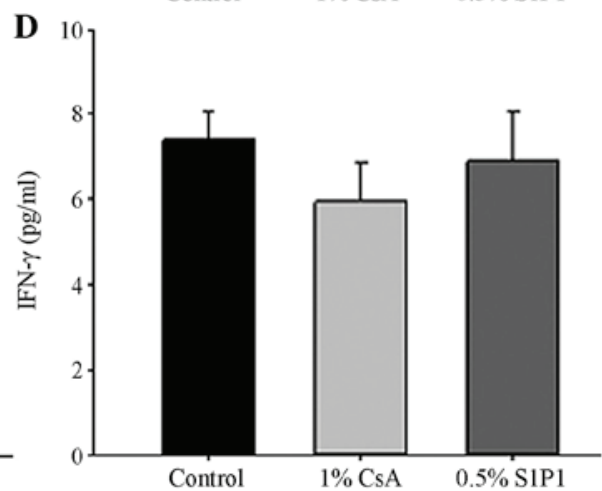

Figure 2. Serum levels of cytokines in each group ( $\mathrm{pg} / \mathrm{ml}, \mathrm{n}=5$ mice/group) were measured by ELISA at postoperative day 30 . "P $<0.05$, compared with the control group. (A) Levels of IL-2; (B) levels of IL-10; (C) levels of TGF- $\beta 1$; (D) levels of IFN- $\gamma$. IL, interleukin; TGF- $\beta 1$, transforming growth factor- $\beta 1$; IFN- $\gamma$, interferon- $\gamma$; S1P1, sphingosine 1-phosphate receptor 1; CsA, cyclosporin A.

A

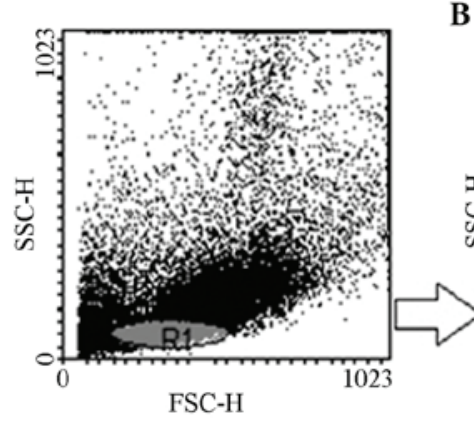

B

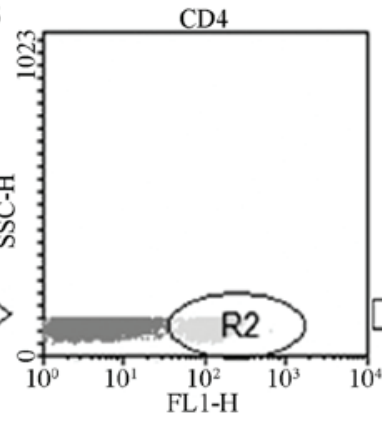

$\mathrm{C}$

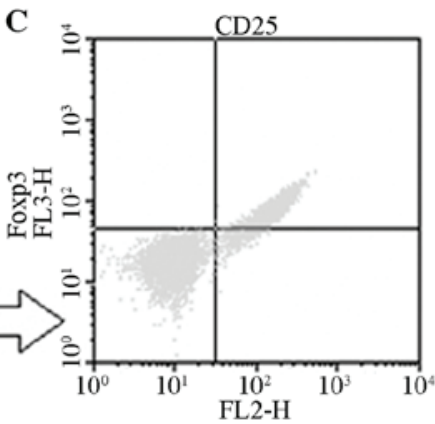

Figure 3. (A) Flow cytometry of the spleen of mouse 2 in the control group. Gate 1, lymphocytes (R1). (B) CD4+ T cells (R2) in lymphocytes. (C) Double labeling of CD25+/Foxp3+ lymphocytes in CD4+ T cells. Gate 2: R1 and R2. S1P1, sphingosine 1-phosphate receptor 1.

nodes, the mean percentage of CD4+CD25+Foxp3+ cells in CD4+ T cells in the spleen in the $0.5 \%$ S1P1 ophthalmic gel group was significantly higher than that in the control group ( $\mathrm{P}=0.046$; Fig. 5C). In addition, a decrease in the percentage of CD4+CD25+Foxp3+ cells in CD4+ T cells in the spleen in the $1 \%$ CsA group was observed ( $\mathrm{P}=0.022$; Fig. 5C).

$q P C R$. The results of mRNA expression in the corneal grafts are revealed in Fig. 6. Compared with the control group, the qPCR analysis demonstrated a reduced mRNA expression pattern of IL-2 in the topical $1 \%$ CsA group $(\mathrm{P}=0.036$; Fig. 6A). The levels of IL-10 mRNA expression in the corneal graft in the topical $1 \%$ CsA group and the $0.5 \%$ S1P1 group were marginally higher than those in the control group, but there was no statistically significant difference among the five groups $(\mathrm{P}>0.05$; Fig. 6B). Compared with the control group, TGF- $\beta 1$ mRNA transcription in the corneal grafts in the topical $0.5 \%$ S1P1 group increased significantly $(\mathrm{P}=0.017$; Fig. 6C). Although the levels of expression of IFN- $\gamma$ mRNA in the corneal grafts in the $1 \% \mathrm{CsA}$ group and the $0.5 \% \mathrm{~S} 1 \mathrm{P} 1$ group were lower than those in the other three groups, there was no statistically significant difference among the three groups (P>0.05; Fig. 6D). The increase in Foxp3 mRNA expression in the corneal grafts in the topical $0.3 \%$ and $0.5 \%$ S1P1 groups was observed, but there was also no statistically significant difference among the three groups $(\mathrm{P}>0.05$; Fig. $6 \mathrm{E})$.

\section{Discussion}

Corneal allotransplantation is the most common type of solid tissue transplantation in humans and is characterized by a high success in graft survival, but immunological rejection 


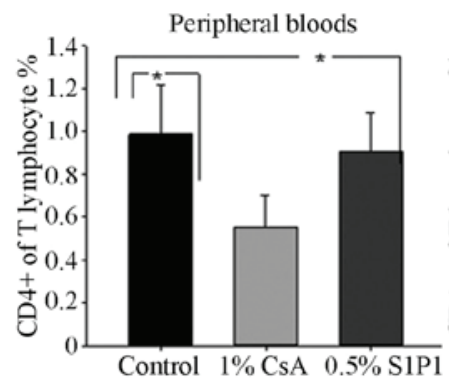

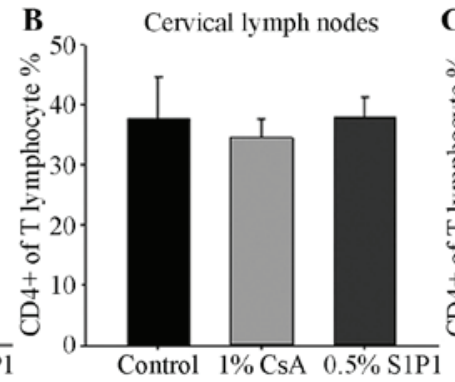

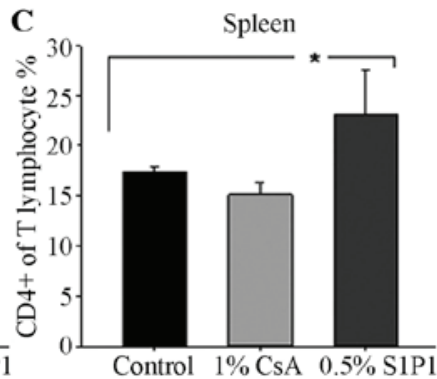

Figure 4. Percentage of CD4+ T cells in lymphocytes in each group (\%, $\mathrm{n}=5$ mice/group) was measured by flow cytometry at postoperative day 30 . ${ }^{*}<0.05$, compared with the control group. (A) Percentage of CD4+ T cells in lymphocytes in peripheral blood. (B) Percentage of CD4+ T cells in lymphocytes in cervical lymph nodes. (C) Percentage of CD4+ T cells in lymphocytes in the spleen. S1P1, sphingosine 1-phosphate receptor 1; CsA, cyclosporin A.

A

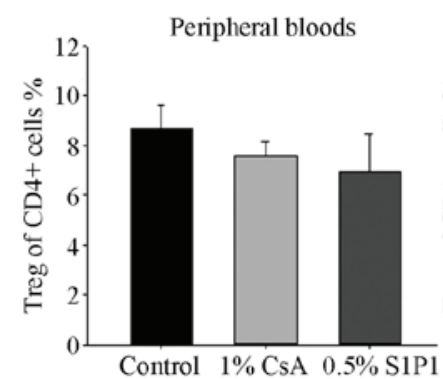

B

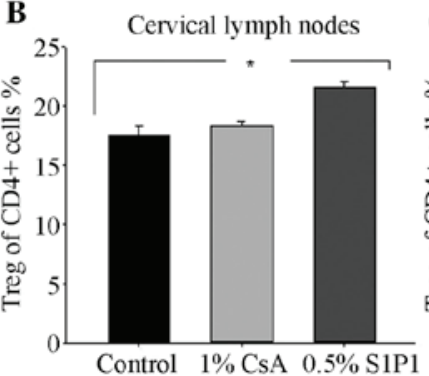

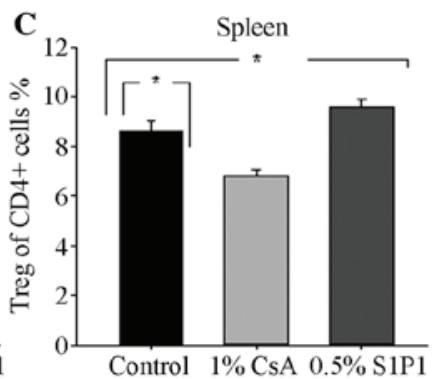

Figure 5. Percentage of CD4+CD25+Foxp3+ T cells (Treg cells) in CD4+ T cells in each group (\%, n=5 mice/group) was measured by flow cytometric analysis at postoperative day 30. ${ }^{\mathrm{P}}<0.05$, compared with the control group. (A) Percentage of $\mathrm{C}$ Treg cells in CD4+ T cells in peripheral bloods. (B) Percentage of $\mathrm{C}$ Treg cells in CD4+ T cells in cervical lymph nodes. (C) Percentage of C Treg cells in CD4+ T cells in the spleen. S1P1, sphingosine 1-phosphate receptor 1; Treg, T regulatory cells; CsA, cyclosporin A

remains a serious risk factor for corneal graft failure $(4-8,24)$. Immunosuppressants, including CsA and FK506, are currently used for the prevention of allograft rejection in clinical corneal transplantation. Although systemic CsA has clear therapeutic efficacy, its use is limited by the potential for systemic side effects (25). Topical CsA has been used and studied extensively with regard to the management of corneal graft rejection in recent years, but the results of a number of studies remain contradictory $(26,27)$. As one of the novel immunosuppressants, systemic treatment with FTY720 has prolonged the corneal graft survival in a number of studies, but there are also certain associated side effects (16-18). The immunomodulator S1P1 as an agonist of G-protein-coupled receptors does not suppress lymphocyte activation and clonal expansion but rather modulates lymphocyte circulation (13). Therefore, the present study investigated the topical application of S1P1 on allografts following corneal transplantation in mice.

In the present study, it was identified that $0.5 \% \mathrm{~S} 1 \mathrm{P} 1$ ophthalmic gel prolonged the survival of mouse corneal allografts effectively. Although Unal et al (28) and Poon A et al (29) demonstrated that topical application of $0.05 \%$ CsA had no significant effect on corneal graft survival, Alalwani et al (30) found that eye drops containing 2\% CsA inhibited corneal rejection effectively. From the results of the present study, it was identified that the application of eye drops containing $1 \% \mathrm{CsA}$ also prolonged corneal graft survival. Therefore, an opthalmic gel containing $0.5 \%$ S1P1 and eye drops containing $1 \% \mathrm{CsA}$ inhibited the rejection of mouse allogeneic corneal grafts effectively.
Although the systemic absorption of topically administered drugs is limited, the present study identified that ophthalmic gel containing $0.5 \% \mathrm{~S} 1 \mathrm{P} 1$ significantly increases the serum levels of TGF- $\beta 1$. TGF- $\beta 1$ is a major type of cytokine expressed in the immune system in mammals (43). It is produced by every leukocyte lineage, including lymphocytes, macrophages and dendritic cells, and its expression serves in both autocrine and paracrine modes to control the differentiation, proliferation and state of activation of these immune cells. TGF- $\beta$ is synthesized as a precursor protein and released in an inactive form as either a small or large latent. It stimulates as well as inhibits cell growth and proliferation (31). Therefore, TGF- $\beta 1$ has been observed as a regulatory molecule, acting to restore balance following deviations from normal levels, and subsequently induce lymphocyte apoptosis (32). Numerous studies have reported that TGF- $\beta$ was produced by Treg cells, controlled T-cell tolerance, and had an important role in the induction of Treg and the maintenance of immunological tolerance $(33,34)$. It was identified that topical application of $0.5 \% \mathrm{~S} 1 \mathrm{P} 1$ enhanced serum levels of TGF- $\beta 1$. Considering its evident inhibitory effect, it was hypothesized that topical application of $0.5 \%$ S1P1 may enhance the immune function of Treg cells with high levels of TGF- $\beta 1$. The present study did not identify any statistically significant difference in the serum levels of IL-2, IL-10 and IFN- $\gamma$ among all of the groups.

Flow cytometric analysis demonstrated that there was a statistically significant difference in the percentage of CD4+ $\mathrm{T}$ cells in the PBLs in the $0.5 \% \mathrm{~S} 1 \mathrm{P} 1$ group. These results 
A

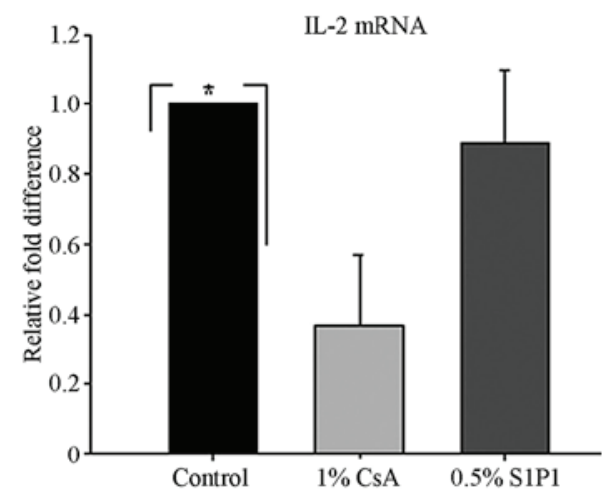

C

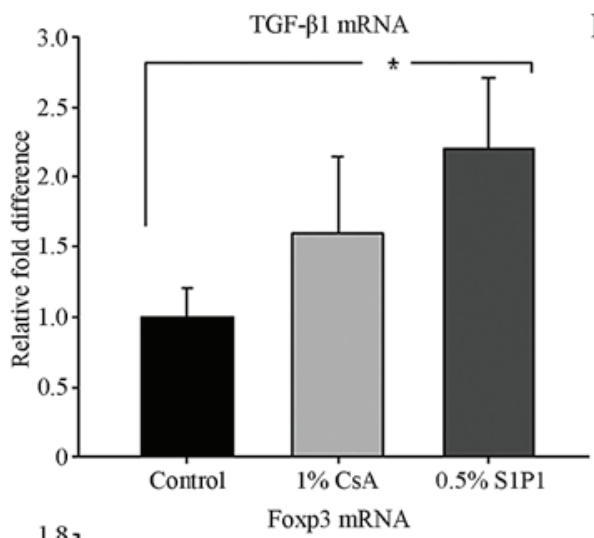

$\mathbf{E}$

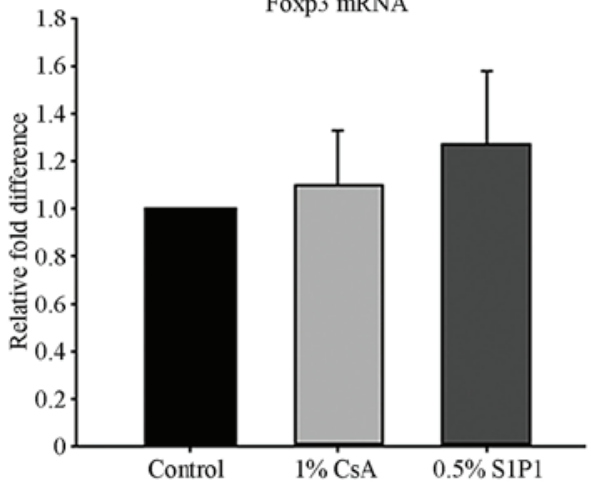

B

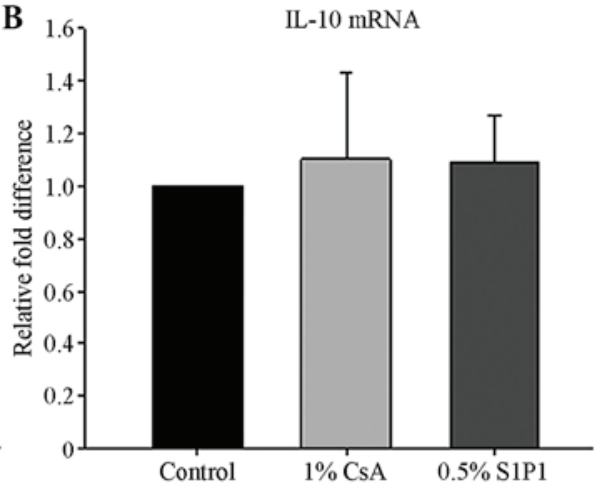

D

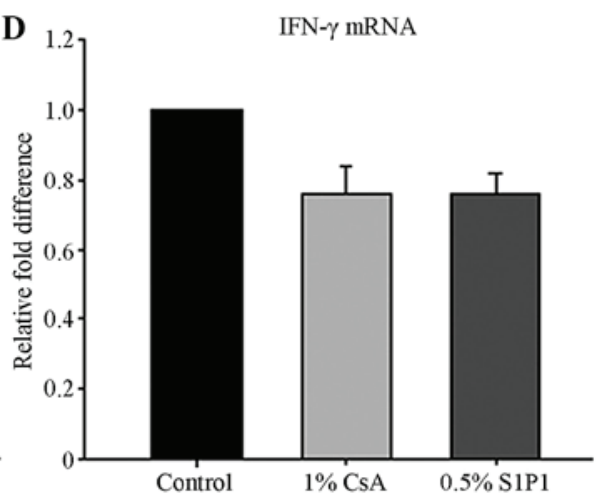

Figure 6. Fold-change in mRNA expression of cytokines in corneal grafts in each group (n=3 mice/group) were measured by quantitative polymerase chain reaction at postoperative day $30 .{ }^{*} \mathrm{P}<0.05$, compared with the control group. (A) IL-2; (B) IL-10; (C) TGF- $\beta 1$; (D) IFN- $\gamma$; (E) Foxp3+. IL, interleukin; TGF- $\beta 1$, transforming growth factor- $\beta 1$; IFN- $\gamma$, interferon- $\gamma$; S1P1, sphingosine 1-phosphate receptor 1 ; CsA, cyclosporin A.

coincided with the results of numerous studies, which had proved that S1P1 induced a severe deprivation in lymphocytes in the blood and induced inhibition of T-cell egress from lymphoid organs due to modification of S1P $(13,15,35)$.

A number of studies had proved that CD4+CD25+Foxp3+ Treg cells were a functionally distinct subset of $\mathrm{T}$ cells with suppressive ability, and that they prevented allograft rejection (36). Matsuoka et al (35) found that CD4+ lymphopenia was a critical factor in Treg-cell homeostasis, and that prolonged imbalance of Treg-cell homeostasis resulted in the loss of tolerance and significant clinical disease manifestations. Furthermore, a number of studies have demonstrated that homing of Treg cells into the draining lymph nodes was required for the suppressive function of these cells (37). For the percentage of CD4+CD25+Foxp3+ T cells in the present study, it was identified that topical application of $0.5 \% \mathrm{~S} 1 \mathrm{P} 1$ enhanced the percentage of CD4+CD25+Foxp3+ $\mathrm{T}$ cells in the lymphoid organs followed by a change in CD4+
T-cell distribution. It has been reported that CD4+CD25+ Treg expressed lower levels of mRNA for S1P1 and S1P4 receptors and demonstrated a reduced chemotactic response to S1P (38). Therefore, it is hypothesized that the immunosuppressive effect of topical $0.5 \% \mathrm{~S} 1 \mathrm{P} 1$ is correlated with a high percentage of CD $4+C D 25+F o x p 3+T$ cells in the lymphoid organs by means of the $\mathrm{S} 1 \mathrm{P}$ receptor. The result is in line with a number of studies, which had proved that S1P1 significantly increased the percentage of Treg cells $(13,14)$.

Flow cytometric analysis identified that the percentage of CD4+ T cells in lymphocytes in PBLs in the topical 1\% CsA group was lower than that in the control group $(\mathrm{P}=0.022)$. This reduction may be explained by the immunosuppressive effect of CsA (39). It was also identified that topical application of $1 \%$ CsA reduced the percentage of CD4+CD25+Foxp3+ $T$ cells in the spleen $(\mathrm{P}<0.001)$. This result was in accordance with several studies, which proved that CsA may also inhibit the function of CD4+CD25+ Treg cells (40). 
In order to further investigate the mechanisms by which topical application of $0.5 \% \mathrm{~S} 1 \mathrm{P} 1$ prolonged corneal allograft survival, the intra-graft mRNA gene expression of cytokines was examined. These cytokines, including IL-12, IL-10, TGF- $\beta 1$, IFN- $\gamma$ and Foxp3 mRNA, were quantified by qPCR. A significant increase in TGF- $\beta 1$ mRNA expression in the topical $0.5 \%$ S1P1 group was observed. Several studies had previously found that Treg cells produced TGF- $\beta 1$ and the suppression of Treg cells was associated with TGF- $\beta 1(33,34)$. Furthermore, Yamagami et al (41) found that draining cervical lymph nodes (CLN) had a critical role in alloimmunity and rejection of high-risk corneal grafts. Therefore, the increase in TGF- $\beta 1$ mRNA expression in corneal grafts may be associated with the higher percentage of CD4+CD25+Foxp3+ T cells in CLN. Therefore, the present study further indicated that topical $0.5 \%$ S1P1 prolonged the survival of corneal grafts by enhancing the functions of Treg cells. It was identified that the IL-2 mRNA expression in the topical 1\% CsA group was lower than that in other groups, which is concordant with the results of other studies, which proved that CsA inhibited the synthesis of IL-2 mRNA (42). In regard to IL-10, IFN- $\gamma$ and Foxp3 mRNA expression, there was no statistically significant difference among the five groups. However, the levels of IL-10 and Foxp3 mRNA in the topical $0.5 \%$ S1P1 group were higher than those in the other groups.

In conclusion, the present study identified that topical application of $0.5 \%$ S1P1 effectively prolonged the survival of mouse allogeneic corneal grafts as well as topical application of $1 \%$ CsA. However, topical $0.5 \%$ S1P1 and topical $1 \%$ CsA suppress corneal graft rejection via different pathways. Topical application of $0.5 \% \mathrm{~S} 1 \mathrm{P} 1$ may increase the percentage of CD4+CD25+Foxp3+ T cells in the lymphoid organs followed by a change in the CD4+ T-cell distribution. It may therefore reduce the infiltration of inflammatory cells, including CD4+ $\mathrm{T}$ lymphocytes, in the corneal graft. It may also enhance the serum levels of TGF- $\beta 1$ and increase the expression of TGF- $\beta 1$ mRNA in corneal grafts.

\section{Acknowledgements}

The present study was supported by National Science Fund of China (grant no. 81170830). The authors are grateful to Dr Zhao-Shan Liu (Institute of Medicine, Academy of Military Medical Sciences, Beijing, China) and Dr Jing-Xiang Huang (Laboratory of Molecular Biology, Institute of Orthopaedics, The General Hospital of People's Liberation Army, Beijing, China) for their excellent technical assistance.

\section{References}

1. Oliva MS, Schottman T and Gulati M: Turning the tide of corneal blindness. Indian J Ophthalmo 160: 423-427, 2012.

2. Streilein JW: New thoughts on the immunology of corneal transplantation. Eye 17: 943-948, 2003

3. Williams KA, Lowe M, Bartlett C, Kelly TL and Coster DJ: Risk factors for human corneal graft failure within the Australian corneal graft registry. Transplantation 86: 1720-1724, 2008.

4. Maguire MG, Stark WJ, Gottsch JD, et al: Risk factors for corneal graft failure and rejection in the collaborative corneal transplantation studies. Collaborative Corneal Transplantation Studies Research Group. Ophthalmology 101: 1536-1547, 1994

5. Panda A, Vanathi M, Kumar A, Dash Y and Priya S: Corneal graft rejection. Surv Ophthalmol 52: 375-396, 2007.
6. Niederkorn JY: Immune mechanisms of corneal allograft rejection. Curr Eye Res 32: 1005-1016, 2007.

7. Chauhan SK, Saban DR, Lee HK and Dana R: Levels of Foxp3 in regulatory $\mathrm{T}$ cells reflect their functional status in transplantation. J Immunol 182: 148-153 2009.

8. Cunnusamy K, Paunicka K, Reyes N, et al: Two different regulatory $\mathrm{T}$ cell populations that promote corneal allograft survival. Invest Ophthalmol Vis Sci 51: 6566-6574, 2010.

9. Inoue K, Kimura C, Amano S, et al: Long-term outcome of systemic cyclosporine treatment following penetrating keratoplasty. Jpn J Ophthalmol 45: 378-382, 2001.

10. Shimazaki J, Den S, Omoto M, et al: Prospective, randomized study of the efficacy of systemic cyclosporine in high-risk corneal transplantation. Am J Ophthalmol 152: 33-39, 2011

11. Zhang ZY, Zhang Z, Zug C, et al: AUY954, a selective S1P1 modulator, prevents experimental autoimmune neuritis. J Neuroimmunol 216: 59-65, 2009.

12. Hanessian S, Charron G, Billich A and Guerini D: Constrained azacyclic analogues of the immunomodulatory agent FTY720 as molecular probes for sphingosine 1-phosphate receptors. Bioorg Med Chem Lett 17: 491-494, 2007.

13. Brinkmann V, Davis MD, Heise CE, et al: The immune modulator FTY720 targets sphingosine 1-phosphate receptors. J Biol Chem 277: 21453-21457, 2002.

14. Pan S, Mi Y, Pally C, et al: A monoselective sphingosine-1-phosphate receptor-1 agonist prevents allograft rejection in a stringent rat heart transplantation model. Chem Biol 13: 1227-1234, 2006

15. Sedláková K, Muckersie E, Robertson M, Filipec M and Forrester JV: FTY720 in corneal concordant xenotransplantation. Transplantation 79: 297-303, 2005.

16. Mayer K, Birnbaum F, Reinhard T, et al: FTY720 prolongs clear corneal allograft survival with a differential effect on different lymphocyte populations. Br J Ophthalmol 88: 915-919, 2004.

17. Zhang EP, Müller A, Ignatius R and Hoffmann F: Significant prolongation of orthotopic corneal-graft survival in FTY720-treated mice. Transplantation 76: 1511-1513, 2003.

18. Cohen JA, Barkhof F, Comi G, et al: Oral fingolimod or intramuscular interferon for relapsing multiple sclerosis. $\mathrm{N}$ Engl J Med 362: 402-415, 2010.

19. Zhang EP, Schrunder S and Hoffmann F: Orthotopic corneal transplantation in the mouse: a new surgical technique with minimal endothelial cell loss. Graefes Arch Clin Exp Ophthalmol 234: 714-719, 1996.

20. Brinkmann V, Cyster JG and Hla T: FYT720: sphingosine 1-phosphate receptor-1 in the control of lymphocyte egress and endothelial barrier function. Am J Transplant 4: 1019-1025, 2004.

21. Zhang JL, Sun DJ, Hou CM, et al: CD3 mAb treatment ameliorated the severity of the cGVHD-induced lupus nephritis in mice by up-regulation of Foxp3+ regulatory T cells in the target tissue: kidney. Transpl Immunol 24: 17-25, 2010.

22. Xie Y, Sun HX and Li D: Platycodin D is a potent adjuvant of specific cellular and humoral immune responses against recombinant hepatitis B antigen. Vaccine 27: 757-764, 2009.

23. Küchle M, Cursiefen C, Nguyen NX, et al: Risk factors for corneal allograft rejection: intermediate results of a prospective normal-risk keratoplasty study. Graefes Arch Clin Exp Ophthalmol 240: 580-584, 2002.

24. Xie L, Shi W, Wang Z, Bei J and Wang S: Prolongation of corneal allograft survival using cyclosporine in a polylactide-co-glycolide polymer. Cornea 20: 748-752, 2001.

25. Bourges JL, Lallemand F, Agla E, et al: Evaluation of a topical cyclosporine A prodrug on corneal graft rejection in rats. Mol Vis 12: 1461-1466, 2006.

26. Sinha R, Jhanji V, Verma K, et al: Efficacy of topical cyclosporine A $2 \%$ in prevention of graft rejection in high-risk keratoplasty: a randomized controlled trial. Graefes Arch Clin Exp Ophthalmol 248: 1167-1172, 2010.

27. Ziaei M and Manzouri B: Topical cyclosporine in corneal transplantation. Cornea 29: Oct 29, 2014 (Epub ahead of print).

28. Unal M and Yucel I\; Evaluation of topical ciclosporin $0.05 \%$ for prevention of rejection in high-risk corneal grafts. Br J Ophthalmol 92: 1411-1414, 2008.

29. Poon A, Constantinou M, Lamoureux E and Taylor HR: Topical Cyclosporin $\mathrm{A}$ in the treatment of acute graft rejection: a randomized controlled trial. Clin Experiment Ophthalmol 36: 415-421, 2008

30. Alalwani H, Omer Saleh B, Rocher N, et al: Advantages and limits of multiple grafts (third keratoplasty) under local cyclosporin 2\%. J Fr Ophtalmol 33: 710-714, 2010 (In French). 
31. Wang GY, Yang Y, Li H, et al: Rapamycin combined with donor immature dendritic cells promotes liver allograft survival in association with CD4(+) CD25(+) Foxp3(+) regulatory T cell expansion. Hepatol Res 42: 192-202, 2012.

32. Lu L, Ma J, Wang X, et al: Synergistic effect of TGF-beta superfamily members on the induction of Foxp $3^{+}$Treg. Eur J Immunol 40: 142-152, 2010.

33. Hofmann U, Hu K, Walter F, et al: Pharmacological pre- and post-conditioning with the sphingosine-1-phosphate receptor modulator FTY720 after myocardial ischaemia-reperfusion. Br J Pharmacol 160: 1243-1251, 2010.

34. Stanojlovic S, Schlickeiser S, Appelt C, et al: Influence of combined treatment of low dose rapamycin and cyclosporin A on corneal allograft survival. Graefes Arch Clin Exp Ophthalmol 248: 1447-1456, 2010.

35. Matsuoka K, Kim HT, McDonough S, et al: Altered regulatory $\mathrm{T}$ cell homeostasis in patients with $\mathrm{CD}^{+}$lymphopenia following allogeneic hematopoietic stem cell transplantation. J Clin Invest 120: 1479-1493, 2010.

36. Schneider MA, Meingassner JG, Lipp M, Moore HD and Rot A $\mathrm{CCR} 7$ is required for the in vivo function of $\mathrm{CD} 4^{+} \mathrm{CD} 25^{+}$regulatory T cells. J Exp Med 204: 735-745, 2007.

37. Commodaro AG, Peron JP, Lopes CT, et al: Evaluation of experimental autoimmune uveitis in mice treated with FTY720. Invest Ophthalmol Vis Sci 51: 2568-74, 2010.
38. Sehrawat S and Rouse BT: Anti-inflammatory effects of FTY720 against viral-induced immunopathology: role of drug-induced conversion of T cells to become Foxp $3^{+}$regulators. J Immunol 180: 7636-7647, 2008.

39. Bocian K, Borysowski J, Wierzbicki P, et al: Rapamycin, unlike cyclosporine A, enhances suppressive functions of in vitro-induced $\mathrm{CD} 4{ }^{+} \mathrm{CD} 25^{+}$Tregs. Nephrol Dial Transplant 25: 710-717, 2010.

40. Zeiser R, Nguyen VH, Beilhack A, et al: Inhibition of $\mathrm{CD} 4{ }^{+} \mathrm{CD} 25^{+}$regulatory T-cell function by calcineurin-dependent interleukin-2 production. Blood 108: 390-399, 2006.

41. Yamagami S, Dana MR and Tsuru T: Draining lymph nodes play an essential role in alloimmunity generated in response to high-risk corneal transplantation. Cornea 21: 405-409, 2002.

42. Kobayashi T, Momoi Y and Iwasaki T: Cyclosporine A inhibits the mRNA expressions of IL-2, IL-4 and IFN-gamma, but not TNF-alpha, in canine mononuclear cells. J Vet Med Sci 69: 887-892, 2007.

43. Li J, Ballim D, Rodríguez M, et al: The anti-proliferative function of the TGF- $\beta 1$ signalling pathwayinvolves the repression of the oncogenic TBX2 by its homologue TBX3. J Biol Chem: Nov 4, 2014 (Epub ahead of print). 